\title{
Titulo: Monitoramento da Estação Sismológica de Rio Claro - RCLB
}

André Felipe Gonçalves De Mario, Universidade Estadual Paulista - UNESP

\section{Resumo}

\begin{tabular}{|l||}
\hline \hline A estação sismológica RCLB foi construída dentro do \\
Projeto "Estruturação crustal da Borda Leste da Bacia do \\
Paraná através da Sismologia", com suporte da FAPESP, \\
Processo N?.2001/05515-1. Em Agosto de 2003 teve \\
inicio o projeto de Iniciação Cientifica - PIBIC \\
"Monitoramento da Estação Sismológica RCLB", tendo \\
como objetivo monitorar a estação sismólogica, \\
garantindo seu perfeito fucionamento, coletando os \\
dados (sismogramas de telessismos) necessários para o \\
cálculo da função do receptor. Neste periodo foram \\
armazenados dados de todos os sismos registrados, \\
sendo que os principais eventos foram identificados e \\
analisados. O tratamento destes dados possibilitou \\
posteriormente o Cálculo da profundidade da \\
descontinuidade de Mohorovicic. Obteve-se um valor \\
médio preliminar para a descontinuidade de Moho em \\
torno de 44-45Km. \\
\hline
\end{tabular}

\section{Introdução}

Em Outubro de 2002 começou a operar a estação sismológica RCLB que foi construída dentro do Projeto "Estruturação crustal da Borda Leste da Bacia do Paraná através da Sismologia", com suporte da FAPESP,

Processo N?.2001/05515-1. Em Agosto de 2003, após estar participando do monitoramento da Estação Sismológica RCLB desde Outubro de 2002, teve inicio o projeto de Iniciação Cientifica "Monitoramento da Estação Sismológica RCLB", PIBIC. Este projeto de pesquisa tem como objetivo dar continuidade ao trabalho que vem sendo realizado no projeto de iniciação cientifica - PIBIC. Visando também o aprofundamento dos conhecimentos do aluno André Felipe Gonçalves De Mario, do terceiro ano do curso de Geologia da Universidade Estadual Paulista - UNESP na área de sismologia e a sua introdução na área de instrumentação geofísica.

O Monitoramento da estação sismológica RCLB tem por objetivo coletar os dados (sismogramas de telessismos) necessários para o cálculo da função do receptor, que por sua vez possibilitará a determinação das principais estruturas crustais, como por exemplo, a descontinuidade de Mohorovicic.

\section{Metodologia/ Problema Investigado}

O projeto foi desenvolvido seguindo os itens relacionados abaixo:

1- Monitoramento e Processamento.

O monitoramento da estação sismológica de Rio Claro é constante e realizado ao longo de todo o projeto, a estação encontra-se em plena operação desde 21 de outubro de 2002. Neste período de trabalho foram identificados vários eventos sísmicos como telessismos e sismos provocados por explosões de pedreiras. $O$ processamento dos dados foram feitos na Work Station Sun Ultra 1, utilizando o software SAC.

\section{2 - Pesquisa Bibliográfica}

A pesquisa realizada neste período focou as estruturas internas da Terra, como também a área de sismologia. Possibilitando o conhecimento necessário para a identificação e o tratamento dos eventos sísmicos registrados, onde foi reconhecida:

\section{- Ondas longitudinais e transversais \\ - Localização do Epicentro \\ - Magnitude do Sismo \\ - Data e hora da sua ocorrência}

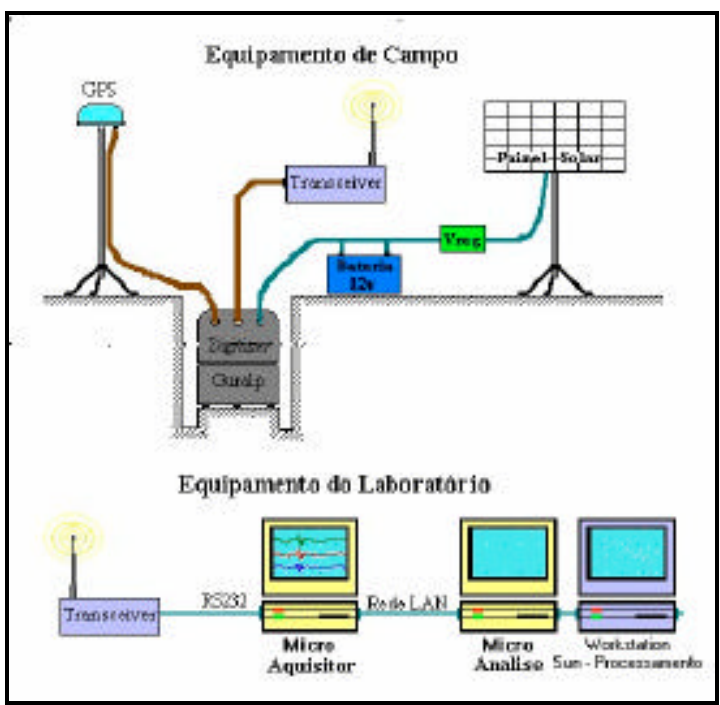

Figura 1: Representação esquemática dos equipamentos necessários para a estação sismológica. (modificada da Figura do Eng ${ }^{\circ}$. Eletrônico Luiz Galhardo F. do IAG-USP). 
Sendo que os principais eventos registrados (Telessismos) foram utilizados para realizar o cálculo da profundidade da descontinuidade de Mohorovicic.

\section{Resultados}

São impressos sismogramas diários da estação sismológica RCLB, quando há ocorrência de algum telessismo ele é identificado através da consulta de um site da Internet http://neic.usgs.gov/ que apresenta boletins diários atualizados sobre os principais eventos ocorridos. Os sismos regionais são identificados em sua maioria através de informações do IAG-USP. Existem também sismos induzidos causados por detonações de pedreiras da região de Rio Claro.

Os principais telessismos registrados são selecionados e processados no programa SAC (Seismic Analysis Code) para a Workstation Sun. Neste processamento é identificada à chegada das ondas sísmicas ( $\mathrm{P}$ e S) e seus respectivos tempos; informações sobre sua localização, magnitude e profundidade. Assim selecionamos os telessismos adequados para a realização da Função do Receptor.

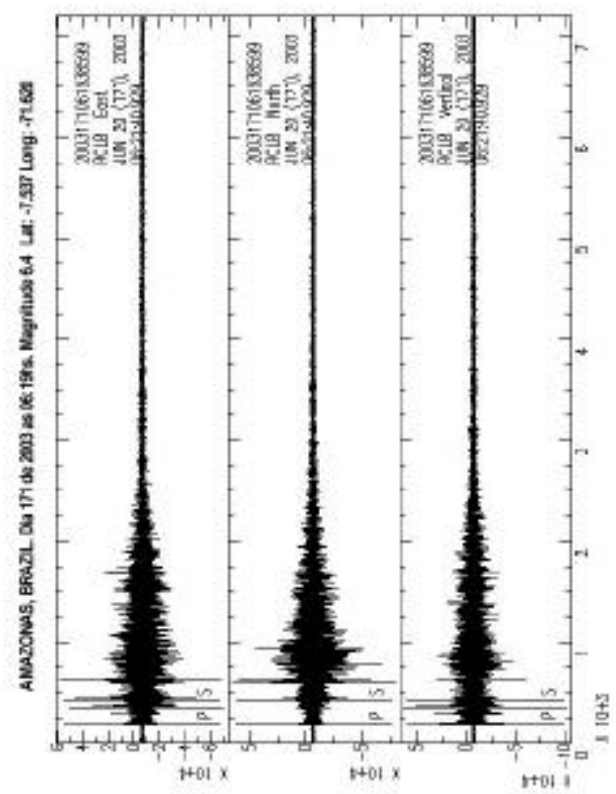

Figura 2: Telessismo Registrado no Brasil.

Para a determinação da função do receptor da estação RCLB, foram utilizadas as rotinas desenvolvidas por Charles J. Ammon, o programa SAC - desenvolvido no Lawrence Livermore National Laboratory (LLNL).

Foram considerados para o calculo da função do receptor os telessismos com distancias epicentrais entre $30^{\circ}$ e $90^{\circ}$ com relação à estação sismológica. Nestas condições as ondas $\mathrm{P}$ atingem a crosta com um ângulo próximo da vertical tendo, portanto amplitudes maiores na componente vertical do sismômetro, enquanto que à parte de sua energia transformada em onda transversal Ps, no processo de refração nas descontinuidades subhorizontais, terá maiores amplitudes nas componentes horizontais. Este fato faz com que no processo de deconvolução, da componente vertical com a horizontal, seja realçada a onda Ps, obtendo-se assim a função do receptor. Porém para alguns cálculos foram consideradas distâncias epicentrais menores que $30^{\circ}$, para incluir alguns sismos importantes que ocorrem na região Andina.

Outro fator importante é a magnitude, então só foram selecionados sismos com magnitude maiores ou iguais a $5 \mathrm{mb}_{\mathrm{b}}$.

Os sismos utilizados para função do receptor através de um script desenvolvido pelo Laboratório de Sismologia do IAG-USP, que consulta o banco de dados dos terremotos da IRIS (Incorporated Research Institutions for Seismology) e colhe os dados necessários para localizar e quantificar os eventos.

Foram trabalhados com mais detalhes para calculo da espessura da crosta os meses de dezembro de 2002 a março de 2003 onde se obteve um valor para a profundidade da Moho variando entre 42 a 47,6 km. Apresentando um valor médio preliminar de aproximadamente $44-45 \mathrm{~km}$.

Verificaram-se resultados anômalos durante 0 cálculo da função do receptor, levantando suspeitas sobre a orientação do Sismômetro que foi feita inicialmente utilizando bússola.

Então foi realizada a locação do Norte Verdadeiro utilizando o método da observação astronômica do sol 
com o Teodolito e o software norteodo.exe cedido pelo Prof. Roberto Bozcko do Departamento de Astronomia do IAG-USP. Verificou-se uma diferença de 10? para Oeste da linha Norte-Sul. Acreditando que a orientação feita com a bússola foi afetada pelo magnetismo do diabásio presente na área aplicou-se a correção calculada pelo método astronômico.

\section{Discussão e Conclusões}

Durante o período em que este projeto vem sendo desenvolvido foi possível inicialmente cumprir uma primeira etapa muito importante que era o monitoramento da estação sismológica e sua coleta de dados, neste primeiro momento aprendeu-se o funcionamento da estação, sua manutenção e a resolução dos problemas que podem ocorrer no dia a dia.

Posteriormente, em uma segunda etapa, realizou-se a análise e o processamento dos dados da estação, selecionando os principais telessismos e os identificando para seu processamento. Os telessismos foram processados, efetuando o cálculo da função do Receptor, obtendo a profundidade da descontinuidade de Moho. Com boas expectativas para o futuro, pretendemos avançar nos estudos das estruturas internas da crosta através da sismologia.

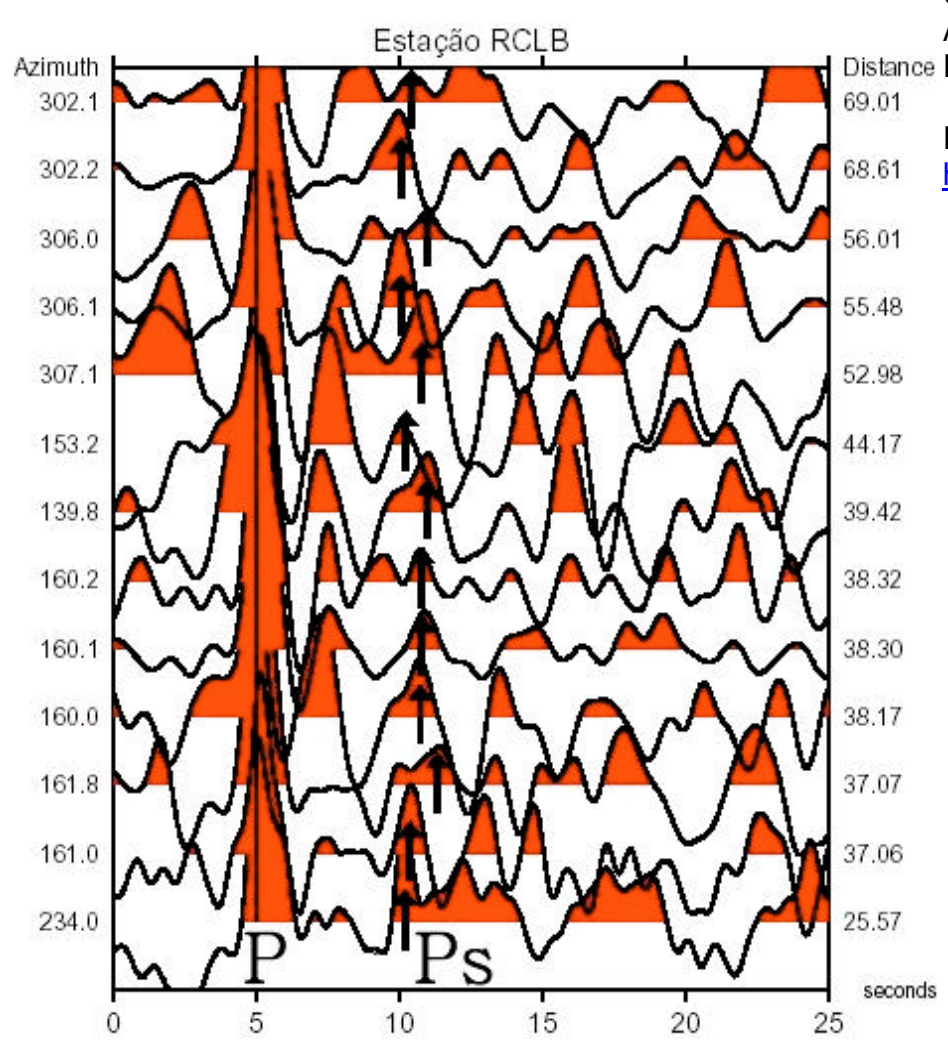

Figura 3 - Função do receptor determinada para os 13 eventos que atenderam ao critério estabelecido de distância e magnitude. A letra $\mathrm{P}$ identifica a onda longitudinal direta e a seta indica a posição temporal da onda Ps. Os eventos estão ordenados de acordo com a distância epicentral, sendo que possui maior distância está situada no topo do gráfico.

\section{Agradecimentos}

Gostaria de agradecer primeiramente minha família que sempre me ajudou e com certeza é uma das grandes responsáveis por eu ter chego até aqui hoje. Também gostaria de agradecer ao Prof. João Carlos Dourado, está fazendo dois anos que trabalhamos juntos e ele foi o responsável pela minha introdução no estudo da geofísica e agradecer também ao CNPq pelo auxilio financeiro. Finalizando gostaria de dedicar este trabalho a minha família e amigos que sempre me ajudaram, obrigado.

\section{Referências}

Teixeira, Wilson; Toeldo, M. Cristina; Fairchild, Thomas; Taioli, Fábio. Decifrando a Terra. São Paulo: Oficina de Textos,

2000.

Dourado, J C; Estruturação crustal da Borda Leste da Bacia do Paraná através da Sismologia. (2001) Inédito.

Gómez, Jesus; Paniágua, Remy; Sismologia. Instituto Astronômico e Geofísico, Universidade de São Paulo. Inédito.

Internet. United States Geological Survey's, 


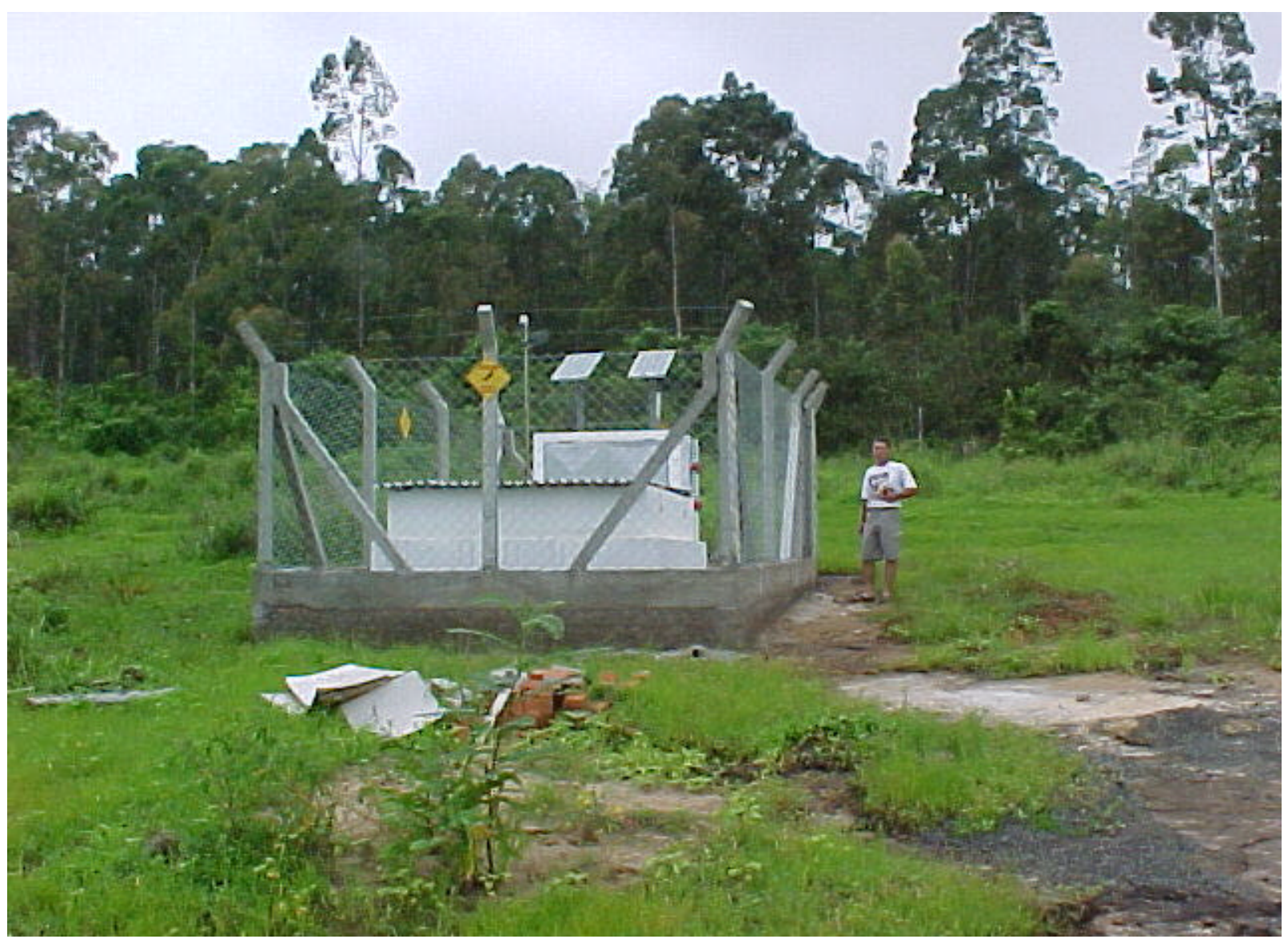

Figura 4: Local das Instalações da Estação Sismológica RCLB. 